\title{
A Comparison between Static and Repeated Load Test to Predict Asphalt Concrete Rut Depth
}

\author{
Farhan Alzaidy \\ Department of Civil Engineering \\ College of Engineering \\ University of Baghdad \\ Baghdad, Iraq \\ f.alzaidy1901m@coeng.uobaghdad.edu.iq
}

\author{
Amjad Hamad Khalil Albayati \\ Department of Civil Engineering \\ College of Engineering \\ University of Baghdad \\ Baghdad, Iraq \\ a.khalil@uobaghdad.edu.iq
}

\begin{abstract}
Rutting has a significant impact on the pavements' performance. Rutting depth is often used as a parameter to assess the quality of pavements. The Asphalt Institute (AI) design method prescribes a maximum allowable rutting depth of $13 \mathrm{~mm}$, whereas the AASHTO design method stipulates a critical serviceability index of 2.5 which is equivalent to an average rutting depth of $15 \mathrm{~mm}$. In this research, static and repeated compression tests were performed to evaluate the permanent strain based on (1) the relationship between mix properties (asphalt content and type), and (2) testing temperature. The results indicated that the accumulated plastic strain was higher during the repeated load test than that during the static load tests. Notably, temperature played a major role. The power-law model was used to describe the relationship between the accumulated permanent strain and the number of load repetitions. Furthermore, graphical analysis was performed using VESYS $5 \mathrm{~W}$ to predict the rut depth for the asphalt concrete layer. The $\alpha$ and $\mu$ parameters affected the predicted rut depth significantly. The results show a substantial difference between the two tests, indicating that the repeated load test is more adequate, useful, and accurate when compared with the static load test for the evaluation of the rut depth.
\end{abstract}

Keywords-asphalt concrete; rut depth; VESYS

\section{INTRODUCTION}

Rutting is a distress mechanism in flexible pavements. Recently, due to the increased truck tire pressures and the lack of maintenance that result in roadway deterioration [1], rutting has become the predominant mode of flexible pavement failures. Rutting is primarily caused by the accumulation of permanent deformations in the pavement or its layers. Furthermore, a major portion of rutting in the surface layer of flexible pavements is subjected to high tire pressures and heavy axle loads. High tire pressures decrease the contact area between the tire and the pavement, producing high stress, which aggravates deformation in flexible pavements. In addition, environmental conditions affect significantly the surface layer of the pavements [2].

The permanent deformation of the Asphalt Concrete (AC) mixture has been studied by several researchers for various materials using different testing procedures. Furthermore, various parameters and prediction models have been developed to measure rutting resistance. In this study, creep and uniaxial cyclic compression results of $\mathrm{AC}$ mixtures were estimated and compared based on various asphalt contents, asphalt types, and temperatures. Many studies have been performed to study the mechanism of rutting, and many methods have been proposed for predicting the Rut Depth (RD). Some of these methods are based on limiting the values of subgrade strain to levels that prevent rutting at the pavement surface. These methods were based on the assumption that when the maximum vertical compressive strain at the top of the subgrade is less than a critical value, rutting will be limited to an acceptable level for a specified number of load applications. However, this methodology does not essentially preclude the occurrence of rutting that might occur in the asphalt layer. Therefore, a layerstrain method was proposed to improve the above process by including additional analysis to evaluate the amount of rutting occurring in the asphalt layer [3]. It is reported [4] that excessive permanent deformation can lead to longitudinal depressions in wheel paths. This can be followed by longitudinal cracking. Subsequently, water can penetrate these cracks and deteriorate the roadway, causing it to lose its loadcarrying capacity. Furthermore, excessive permanent deformation can reduce the driving comfort and can lead to icing or hydroplaning because of water getting collected in wheel paths.

AASHTO classified traffic control and environmental factors as the major causes of AC rutting. However, highway authorities have little control over these two factors. Furthermore, there are some limitations that prevent the redressing of problems that are within the control of highway agencies [5]. Several highway engineers focused on ascertaining the factors that can help address the problem of rutting to propose better mechanisms to reduce the RD. Authors in [6] performed several creep tests to study the permanent deformation of $\mathrm{AC}$ and developed a rutting prediction model based on a statistical method which considered factors such as stress, temperature, asphalt viscosity, effective asphalt content, air voids, and load repetition. To evaluate the parameters that affect the $\mathrm{AC}$ mix, authors in [7] evaluated the influencing factors and suggested variables such as the asphalt content, binder viscosity, air voids, and test temperature that affect the $\mathrm{AC}$ mix. 
Furthermore, additives were also used to improve the strength of asphalt materials, e.g. using rubber modified asphalt binder [8]. Most of the existing permanent deformation models for asphalt mixes have been empirically determined based on laboratory test results. As a simple performance test [9], a uniaxial repeated load test is generally used to characterize the permanent deformation response of asphalt mixes. Permanent deformation measured using repeated load tests, as depicted in Figure 1, is generally composed of three stages [10], primary, secondary, and tertiary. In the primary stage, the rate of permanent deformation accumulates quickly and tends to decrease, reaching a constant value in the secondary stage. Finally, the rate starts to increase rapidly and accumulates again in the tertiary stage [11]. The objective of these tests is to simulate the repeated load conditions that occur on the road. Authors in [12] compared the responses of 3 mixes consisting of conventional and modified binders under both creep and repeated loading. For creep loading at $37^{\circ} \mathrm{C}$ and confining pressure of $207 \mathrm{KPa}$, the difference among the mixes was not discernible. The results of repeated load testing suggest that the repeated loading test may be more applicable than the creep test to calculate the permanent deformation characteristics of asphalt mixes. The results of Strategic Highway Research Program (SHRP) [13] also suggest that more deformation occurs in repeated loading than in creep loading for the same materials and other test conditions. Apart from the two conventional procedures used for repeated load tests, i.e. termination of the test at 10,000 loading cycles or $5 \%$ accumulated strain, regression coefficients $a$ (intercept) and $b$ (slope) were also used to determine the rutting susceptibility of AC mixtures [14]. Authors in [15] proposed a method based on repeated axial load tests to determine the flow number of bituminous mixtures. Static and repeated load tests were used to evaluate the rutting potential of asphalt mixtures, and the results indicated that the specimens of mixtures experienced a tertiary flow state in the repeated load test. However, no specimen achieved a tertiary flow state in the static load test. This can be attributed to the static pattern of loading that induces less strain when compared with that of repeated loading [16].

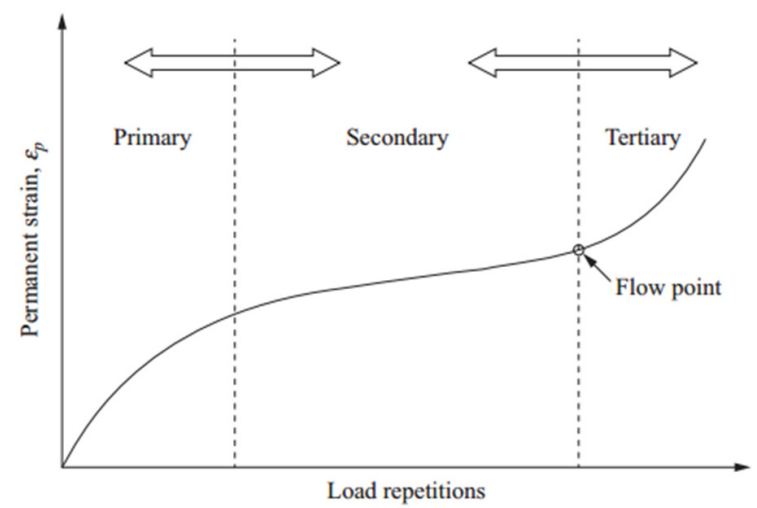

Fig. 1. Typical permanent deformation behavior of asphalt mixture

\section{MATERIALS CHARACTERIZATION}

\section{A. Asphalt Cement}

To characterize the properties of the base bitumen, conventional tests such as the penetration test, softening point test, flash point test, and penetration and ductility after the thinfilm oven test were performed. These tests were performed in conformity with the relevant test parameters listed in Table I.

TABLE I. PROPERTIES OF ASPHALT CEMENT

\begin{tabular}{|c|c|c|c|c|c|}
\hline \multirow{2}{*}{ Property } & \multirow{2}{*}{$\begin{array}{c}\text { ASTM } \\
\text { design } \\
\text { ation }\end{array}$} & \multicolumn{2}{|c|}{$\begin{array}{c}\text { Penetration grade } \\
\mathbf{4 0 - 5 0} \\
\end{array}$} & \multicolumn{2}{|c|}{$\begin{array}{c}\text { Penetration grade } \\
60-70 \\
\end{array}$} \\
\hline & & $\begin{array}{c}\text { Test } \\
\text { results }\end{array}$ & $\begin{array}{c}\text { SCRB } \\
\text { specification }\end{array}$ & $\begin{array}{l}\text { Test } \\
\text { results }\end{array}$ & $\begin{array}{c}\text { SCRB } \\
\text { specific }\end{array}$ \\
\hline $\begin{array}{l}\text { Penetration } \\
25^{\circ} \mathrm{C}, 100 \mathrm{gm}, 5 \mathrm{~s} \\
(0.1 \mathrm{~mm})\end{array}$ & D-5 & 42 & $40-50$ & 67 & $60-70$ \\
\hline $\begin{array}{l}\text { Softening point } \\
\left({ }^{\circ} \mathrm{C}\right)\end{array}$ & D-36 & 51 & $\ldots$ & 45 & $\cdots \cdots$ \\
\hline $\begin{array}{l}\text { Ductility at } 25^{\circ} \mathrm{C}, \\
5 \mathrm{~cm} / \mathrm{min}(\mathrm{cm})\end{array}$ & D-113 & $>100$ & $>100$ & $\cdots$ & $>100$ \\
\hline Flash point $\left({ }^{\circ} \mathrm{C}\right)$ & D-92 & 289 & Min. 232 & 292 & Min. 232 \\
\hline Specific gravity & D-70 & 1.041 & $\ldots \ldots$ & 1.028 & $\ldots \ldots$ \\
\hline $\begin{array}{l}\text { Residue from } \\
\text { thin-film oven } \\
\text { test: } \\
\text {-Retained } \\
\text { penetration ( } \% \text { of } \\
\text { original) }\end{array}$ & D-1754 & 59.5 & $55+$ & 64.1 & $52+$ \\
\hline $\begin{array}{l}\text {-Ductility at } 25^{\circ} \mathrm{C}, \\
5 \mathrm{~cm} / \mathrm{min}(\mathrm{cm})\end{array}$ & D-113 & 80 & $25+$ & $100+$ & $50+$ \\
\hline
\end{tabular}

\section{B. Aggregates}

Coarse and fine aggregates were chosen and mixed in appropriate proportions to meet the wearing course gradation prescribed by the SCRB specification (SCRB, R/9 2003). The gradation curve of the aggregates is depicted in Figure 2. To obtain the properties of the coarse and fine aggregates used in the mixture, conventional tests, such as the specific gravity test, Los Angeles abrasion resistance test, sodium sulfate soundness test, and sand equivalent test were performed. The results, along with the specification limits set by the SCRB, are listed in Table II.

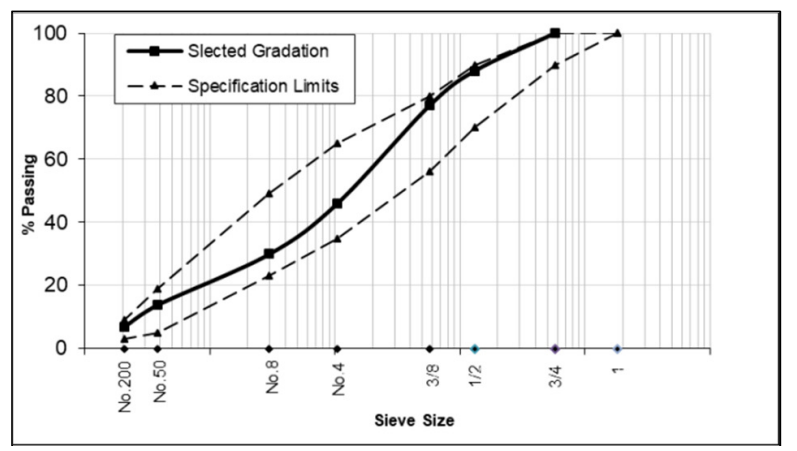

Fig. 2. Aggregate gradation curve.

\section{Mineral Filler}

The filler is a non-plastic material that must pass through sieve No. $200(0.075 \mathrm{~mm})$. The physical properties of the filler used in this study are listed in Table III. 
TABLE II. PHYSICAL PROPERTIES OF AGGREGATES

\begin{tabular}{|l|c|c|c|}
\hline \multicolumn{1}{|c|}{ Property } & $\begin{array}{c}\text { ASTM } \\
\text { designation }\end{array}$ & $\begin{array}{c}\text { Test } \\
\text { results }\end{array}$ & $\begin{array}{c}\text { SCRB } \\
\text { specification }\end{array}$ \\
\hline Coarse aggregates: & & & \\
1. Bulk specific gravity & $\mathrm{C}-127$ & 2.611 & $\ldots \ldots$ \\
2. Apparent specific gravity & & 2.689 & $\ldots \ldots$ \\
3. Water absorption (\%) & & 0.443 & $\ldots \ldots$ \\
4. Wear by Los Angeles & $\mathrm{C}-131$ & 18.7 & $30 \mathrm{max}$. \\
abrasion (\%) & & & \\
5. Soundness loss by sodium & $\mathrm{C}-88$ & 3.1 & $10 \mathrm{max}$. \\
sulfate solution (\%) & & & \\
6. Fractured pieces (\%) & & 96 & $95 \mathrm{~min}$. \\
\hline Fine aggregates: & & & \\
1. Bulk specific gravity & $\mathrm{C}-127$ & 2.663 & \\
2. Apparent specific gravity & & 2.697 & \\
3. Water absorption (\%) & & 0.727 & \\
4. Sand equivalent (\%) & 2419 & 55 & $45 \mathrm{~min}$. \\
\hline
\end{tabular}

TABLE III. PHYSICAL PROPERTIES OF THE MINERAL FILLER (LIMESTONE DUST)

\begin{tabular}{|c|c|}
\hline Property & Test results \\
\hline Specific gravity & 2.794 \\
\hline Passing sieve No. $200(0.075 \mathrm{~mm})$ & 94 \\
\hline
\end{tabular}

\section{Specimen Preparation}

The cylindrical specimens used in this study were $101.6 \mathrm{~mm}$ (4in) in diameter and $203.2 \mathrm{~mm}$ (8in) in height. The fractions of the aggregates were separated into groups and the aggregates retained on the pan were discarded and replaced by the mineral filler (limestone dust). Based on the graduation specifications depicted in Figure 2, the aggregates were mixed into a batch of $3800 \mathrm{~g}$ on the mixing bowl and heated to $150^{\circ} \mathrm{C}$ in a temperature-controlled oven. Asphalt was also heated in a container to a temperature in the range of $135-140^{\circ} \mathrm{C}$ for $2 \mathrm{~min}$, and the contents of the bowel were thoroughly mixed manually on a hot plate. To ensure a uniform compaction temperature, the bowel with its contents was transferred to an oven and stored for $10 \mathrm{~min}$ at $140^{\circ} \mathrm{C}$. A preheated to $100^{\circ} \mathrm{C}$ compaction mold was prepared and a 4-in paper disk was inserted to cover the mold base plate. The interior edge of the mold was lubricated using a brush to facilitate the specimen extraction. The specimen was compacted by the double plunger method with a load of $65000 \mathrm{lb}(29491 \mathrm{~kg})$ applied using a hydraulic compression machine at the Material Laboratory of the Civil Engineering Department of the University of Baghdad. The load was applied to each end of the specimen for $1 \mathrm{~min}$. Finally, 36 specimens were carefully transferred to a smooth, flat surface and allowed to cool overnight at $25^{\circ} \mathrm{C}$ and then were removed from the mold using a hydraulic extractor. The specimens were then numbered and stored in a bag.

\section{EVALUATION OF PERMANENT DEFORMATION AND TESTING RESULTS}

Permanent strain values were determined using a Pneumatic Repeated Load System (PRLS) apparatus manufactured under the auspices of the Civil Engineering Department of the University of Baghdad [17] as depicted in Figure 3. Axial repeated and static load tests were performed. The cylindrical specimens, $101.6 \mathrm{~mm}$ (4in) in diameter and $203.2 \mathrm{~mm}(8 \mathrm{in})$ in height, were subjected to conditioning in the PRLS test chamber at various testing temperatures $\left(20^{\circ} \mathrm{C}, 40^{\circ} \mathrm{C}\right.$, and $60^{\circ} \mathrm{C}$ ) for $2 \mathrm{~h}$. A linear variable differential transformer was used to monitor the deformation of the specimens under each load cycle. Compressive loading was applied at $138 \mathrm{kPa}$ in the form of a rectangular wave with a constant loading frequency of $60 \mathrm{cycles} / \mathrm{min}$ and loading sequence including $0.1 \mathrm{~s}$ load duration and $0.9 \mathrm{~s}$ rest duration.

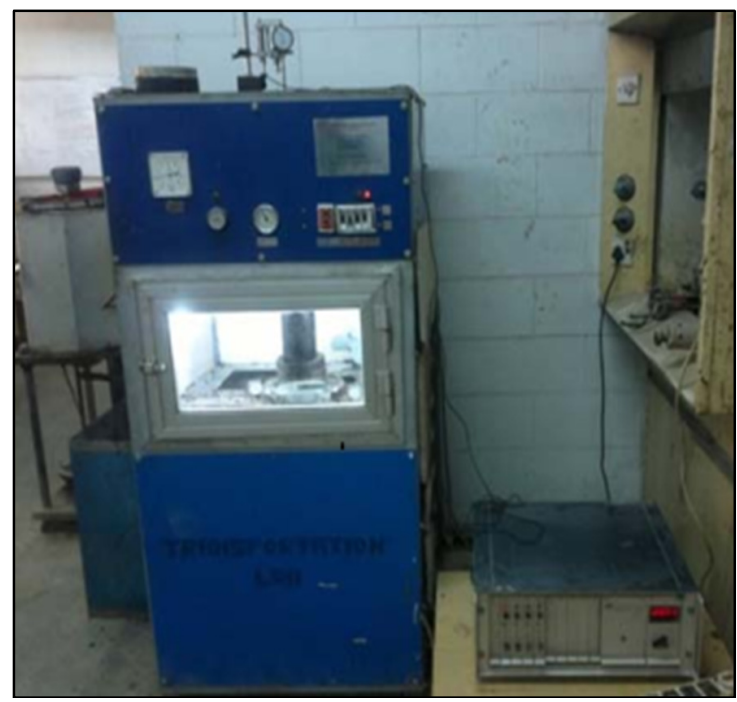

Fig. 3. A photograph of the PRLS.

\section{A. Permanent Deformation Characteristic Properties for Repeated Load Test}

The values of the permanent strain were obtained at the following load repetitions: 1, 2, 10, 100, 500, 1000, 2000, 3000, 4000, 5000, 6000, 7000, 8000, 9000, and 10000 . Permanent strain $\left(\varepsilon_{p}\right)$ was calculated using (1):

$$
\varepsilon_{p}=\frac{p_{d} \times 10^{6}}{h}
$$

where $\varepsilon_{p}$ is the axial permanent microstrain, $p_{d}$ is the axial permanent deformation, and $h$ is the specimen's height. The accumulative axial permanent strain versus the number of loading repetitions $(N)$ is depicted in Figure 4.

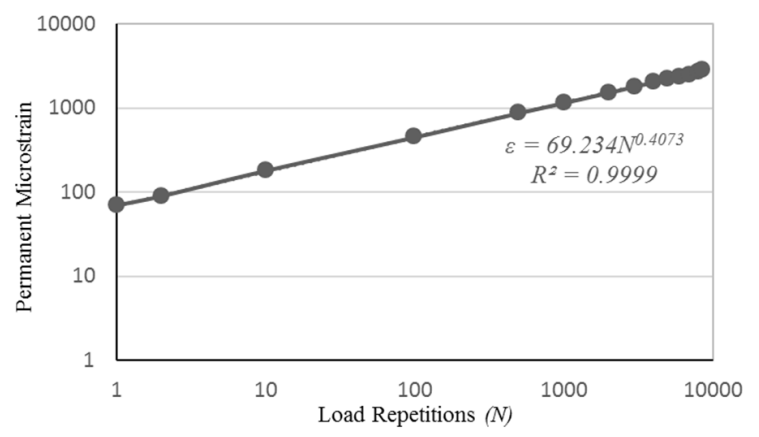

Fig. 4. Cumulative permanent strain vs loading cycles from the repeated load test (log-log scale). 


\section{B. Permanent Deformation Characteristic Properties for Static (Creep) Load Test}

Data for the following loadings were recorded at $1,10,30$, $60,100,260,360,500,1000,2000$, and 3000s. The values of the permanent strain were calculated at these loadings using the following expression:

$$
\varepsilon_{p}=\frac{c_{d} \times 10^{6}}{h}
$$

where $c_{d}$ is the axial creep deformation. The cumulative axial permanent strain versus the number of loading times is depicted in Figure 5.

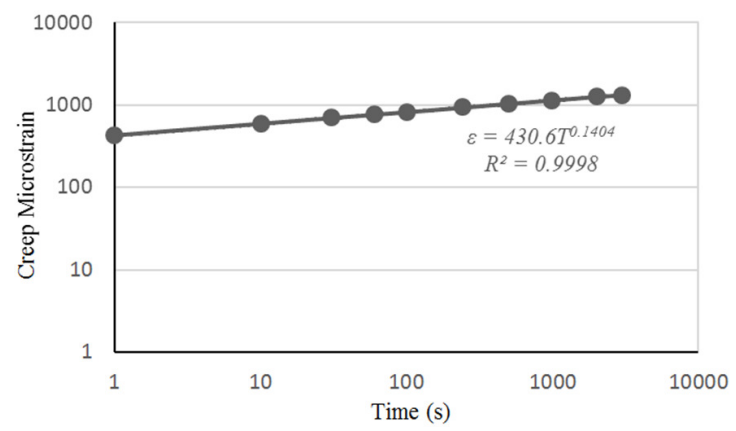

Fig. 5. Cumulative permanent strain vs loading times from the creep load test (log-log scale).

\section{Regression Analysis}

Several formulas have been proposed to describe the relationship between $\varepsilon_{p}$ and $N$. Authors in $[18,19]$ suggested a $\log -\log$ relationship, as described in the following equation:

$$
\varepsilon_{p}=a N^{b}
$$

where $N$ is the number of load repetitions, and $a$ and $b$ are positive regression constants, as depicted in Figure 4. The parameter $a$ is the intercept with the permanent strain axis, and $b$ is the slope of the linear portion of the logarithmic relationship. The double-logarithmic-scaled relationship between $\varepsilon_{p}$ and $N$ can be approximated using a linear function.

\section{VESYS THEORY}

Authors in [20] developed the VESYS software using multilayer visco-elastic theory to predict the RD in flexible pavement layers. The basic assumption of VESYS rutting models is that permanent strain is related to resilient strain as follows:

$$
\varepsilon_{p}(N)=\varepsilon_{r} \mu N^{-\alpha}
$$

where $\varepsilon_{p}(N)$ is the vertical permanent strain at the $N^{\text {th }}$ load repetition, and $\mu$ and $\alpha$ are material properties that are functions of the stress state and temperature respectively. The material parameters are defined as $\alpha=1-b$ and $\mu=a b / \varepsilon_{r}$. These two parameters govern the permanent deformation behavior of the model. In particular, $\alpha$ is the rate of decrease or increase in permanent deformation as the number of load applications increases, and $\mu$ is the constant of proportionality between permanent and elastic strains $(\mu>0)$. Values greater than 1 indicate premature rutting. The most critical task in using this model is the prediction of $\alpha$ and $\mu$ accurately for each pavement layer within the pavement system. The permanent deformation parameters could be predicted using laboratory or field data [21].

The comparative evaluation of the impact of repeated and creep stresses on permanent deformation parameters is listed in Table IV. Intercept $a$ represents the deformation of the specimen after the first load repetition, whereas slope $b$ refers to the rate of deformation throughout the fatigue life of asphalt concrete. Furthermore, this comparison also includes the average values of permanent strain and parameters $\alpha$ and $\beta$.

TABLE IV. PERMANENT DEFORMATION PARAMETERS

\begin{tabular}{|c|c|c|c|c|c|c|c|c|c|}
\hline \multirow{8}{*}{} & \multicolumn{8}{|c|}{ Temperature $\left({ }^{\circ} \mathbf{C}\right)$} & \multicolumn{2}{c|}{ Asphalt content (\%) } & \multicolumn{2}{c|}{ Asphalt grade } \\
\cline { 2 - 10 } & 20 & 40 & 60 & 4 & 4.6 & 5.2 & $40-50$ & $60-70$ \\
\hline \multicolumn{8}{|c|}{ Repeated Load Test (RLT) } \\
\hline $\boldsymbol{\varepsilon}_{\boldsymbol{p}}$ & 266 & 5840 & 30000 & 9458 & 16160 & 16700 & 11160 & 17040 \\
\hline $\boldsymbol{a}$ & 55 & 150 & 430 & 230 & 210 & 190 & 160 & 260 \\
\hline $\boldsymbol{b}$ & 0.184 & 0.40 & 0.58 & 0.348 & 0.4 & 0.43 & 0.394 & 0.398 \\
\hline $\boldsymbol{\alpha}$ & 0.816 & 0.60 & 0.42 & 0.652 & 0.6 & 0.57 & 0.606 & 0.602 \\
\hline $\boldsymbol{\mu}$ & 0.105 & 0.270 & 0.50 & 0.340 & 0.285 & 0.250 & 0.23 & 0.36 \\
\hline \multicolumn{8}{|c|}{ Creep Load Test (CLT) } \\
\hline $\boldsymbol{\varepsilon}_{\boldsymbol{p}}$ & 532 & 1730 & 9295 & 3850 & 3480 & 4219 & 3680 & 4020 \\
\hline $\boldsymbol{a}$ & 210 & 555 & 1430 & 798 & 660 & 730 & 690 & 770 \\
\hline $\boldsymbol{b}$ & 0.119 & 0.144 & 0.264 & 0.165 & 0.176 & 0.187 & 0.175 & 0.177 \\
\hline $\boldsymbol{\alpha}$ & 0.881 & 0.856 & 0.736 & 0.835 & 0.824 & 0.813 & 0.825 & 0.823 \\
\hline $\boldsymbol{\mu}$ & 0.120 & 0.145 & 0.260 & 0.165 & 0.175 & 0.189 & 0.176 & 0.178 \\
\hline
\end{tabular}

\section{DISCUSSION}

The accumulated strain at the flow number increased for the Repeated Load Test (RLT) and exhibited the opposite behavior for the Static Load Test (SLT). The significant difference in the values of $\varepsilon_{p}$ at the failure load for both tests is illustrated in Figure 6. Table V lists the ANOVA analysis that explains the impacts of the testing variables on the plastic strain. The Table lists the degrees of freedom (the number of variables used minus one), the F-test results, and the p-value (significance) for each test. The results particularly indicate that temperature plays a major role affecting plastic deformation ( $F$ value $>>$ $\left.F_{\text {crit. }}.\right)$. The variables (intercept and slope) used in this model when plotted on a log scale can be useful indicators of rutting resistance. The minimal values of each provide a good indicator of rutting resistance. Furthermore, the slope coefficient $b$ is also used as a term of creep rate $(f c)$ to an assessment of the asphalt performance in resistance to permanent deformation. The intercept values of RLT increased by 2.7 and 7.8 factors with an increase in temperature from $20^{\circ} \mathrm{C}$ to $40^{\circ} \mathrm{C}$ and $60^{\circ} \mathrm{C}$ respectively, whereas SLT increased by 2.6 and 6.8 respectively. The content and grade of the asphalt had only a minor impact. The slope or $f c$ values for RLT increased by 2.17 and 3.15 with an increase in temperature from $20^{\circ} \mathrm{C}$ to $40^{\circ} \mathrm{C}$ and $60^{\circ} \mathrm{C}$ respectively, whereas that of SLT increased by 1.21 and 2.21 respectively. The content and grade of the asphalt did not affect the slope of the SLT. The sensitivity analysis of the VESYS $5 \mathrm{~W}$ rutting model clearly indicated that $\alpha$ and $\mu$ had a considerable effect on the predicted $\mathrm{RD}$. The values of both parameters were measured using RLT and SLT. Figures 7-9 illustrate the impact of temperature and mixture properties (asphalt content and grade) 
on the $\mathrm{RD}$ of the $\mathrm{AC}$ layer. As mentioned above, temperature is considered to be the main factor that affects rutting in the AC layer. The results indicated that RD increased with an increase in temperature for both tests, as depicted in Figure 7. At $20^{\circ} \mathrm{C}$, the RD increased slightly. However, at $40^{\circ} \mathrm{C}$ and $60^{\circ} \mathrm{C}$, the RD value was larger for RLT than for SLT by a factor of 6.8 and 4.02 respectively. The asphalt content and grade had no effect on the RD for the creep test, as depicted in Figures 8 and 9. The higher value of $\alpha$ and lower value of $\mu$ coefficients indicate pavements with lower rutting. At a lower value of $\alpha$, rutting will develop over the entire pavement life and the mainstream of the rutting will occur at the initial stage and taper off with the remaining life of the pavement when the AC layer is soft (higher initial strain) or the climatic region is hot (higher temperatures).

(a)

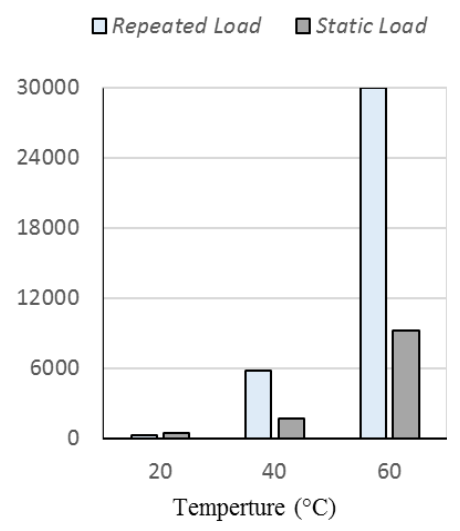

(b)

$\square$ Repeated Load $\quad \square$ Static Load

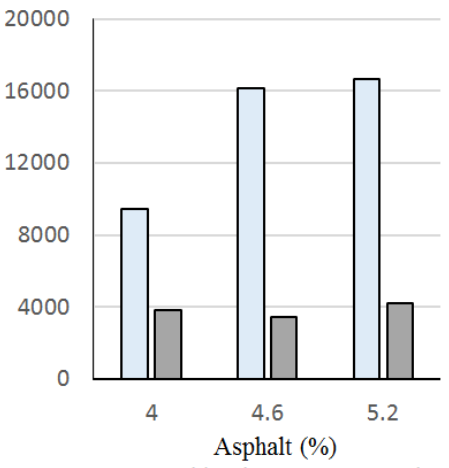

$\square$ Repeated load $\quad \square$ Static Load

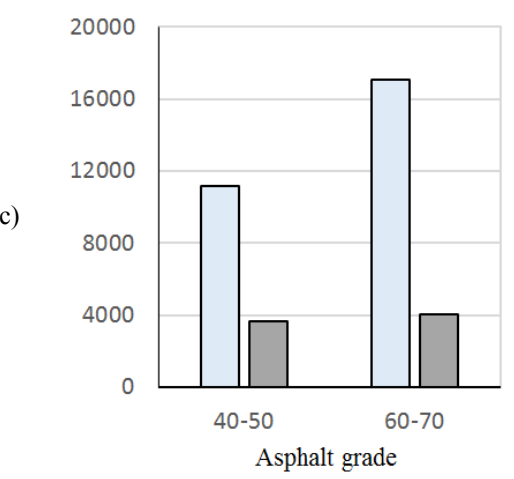

Fig. 6. Impact of testing temperature and asphalt mixture on the plastic
TABLE V. IMPACT OF VARIABLES AND TEST METHODS ON PLASTIC STRAIN ( WO-WAY ANOVA)

\begin{tabular}{|c|c|c|c|c|}
\hline Source of Variation & df & F & P-value & F crit. \\
\hline \multicolumn{5}{|c|}{ Repeated Load Test (RLT) } \\
\hline Temperature ( $\left.{ }^{\circ} \mathbf{C}\right)$ & 2.000 & 38.474 & $6.03 \mathrm{E}-06$ & 3.885 \\
\hline Asphalt grade & 1.000 & 2.666 & 0.128 & 4.747 \\
\hline Asphalt content (\%) & 2.000 & 1.381 & 0.310 & 3.326 \\
\hline \multicolumn{5}{|c|}{ Static Load Test (SLT) } \\
\hline Temperature ( ${ }^{\circ} \mathbf{C )}$ & 2.000 & 291.438 & $6.74 \mathrm{E}-11$ & 3.885 \\
\hline Asphalt grade & 1.000 & 1.096 & 0.316 & 4.747 \\
\hline Asphalt content (\%) & 2.000 & 1.149 & 0.396 & 3.326 \\
\hline
\end{tabular}

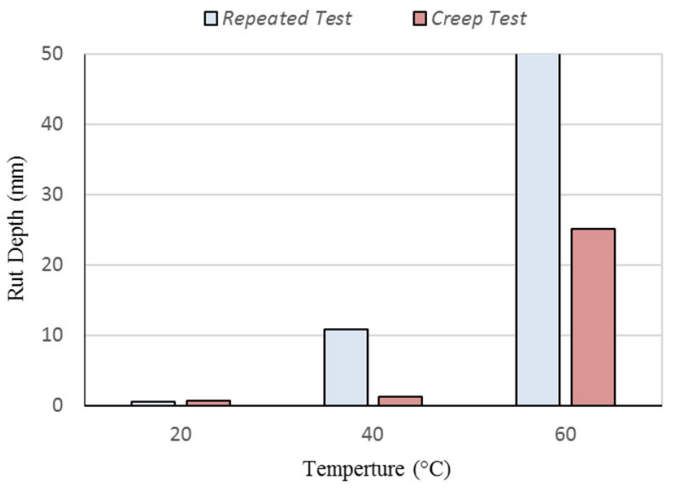

Fig. 7. Temperature vs predicted rut depth on AC layer (VESYS 5W analysis).

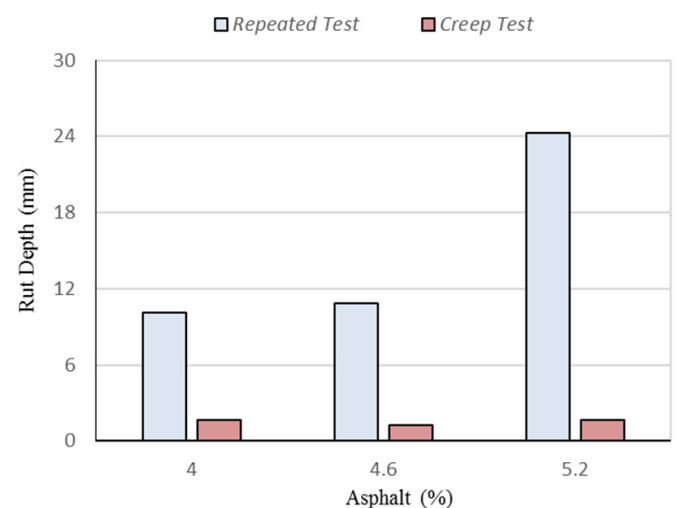

Fig. 8. Asphalt content vs predicted rut depth on $\mathrm{AC}$ layer at $40^{\circ} \mathrm{C}$ (VESYS 5W analysis).

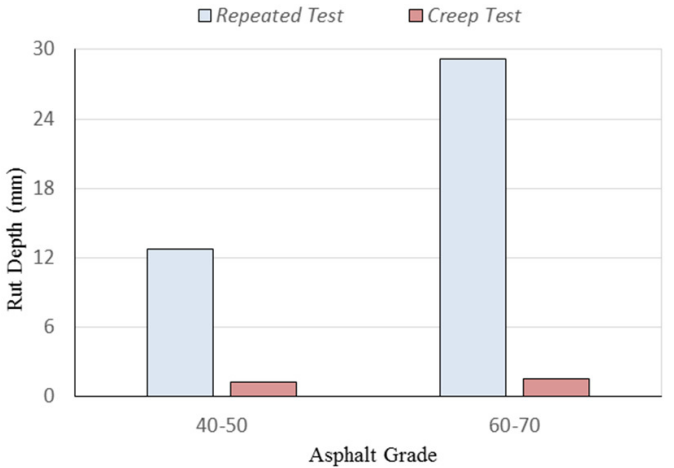

Fig. 9. Asphalt grade vs predicted rut depth on AC layer at $40^{\circ} \mathrm{C}$ (VESYS $5 \mathrm{~W}$ analysis). 


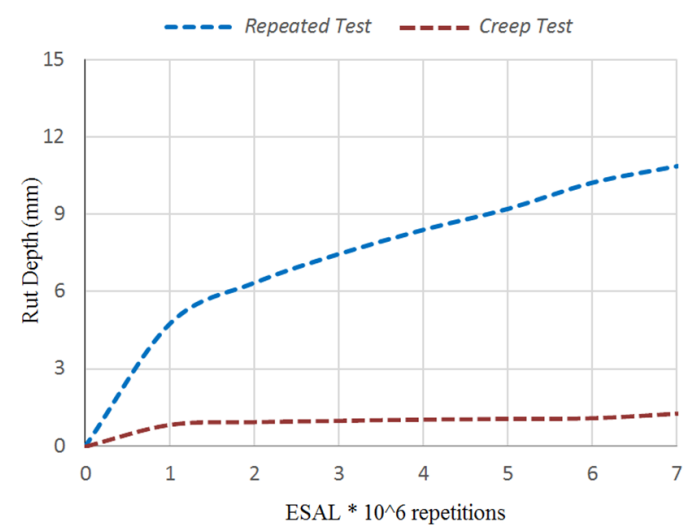

Fig. 10. Impact of ESAL on the prediction of rut depth in $\mathrm{AC}$ layer at $40^{\circ} \mathrm{C}$ (VESYS 5W analysis).

To compare the trend of variation in $\mathrm{RD}$ with equivalent single-axle load (ESAL), Figure 10 depicts the application of various ESALs on the AC layer. The total RD for RLT is higher than that for SLT by a factor of 8.4. Therefore, it is significant that the $\mathrm{RD}$ at the first million repetitions is approximately the $44 \%$ of the total $\mathrm{RD}$. Moreover, we can compare the predicted $\mathrm{RD}$ for the $\mathrm{AC}$ layer evaluated using RLT with the measured RD estimated using (5):

$$
R_{d}=\varepsilon_{p} \times h
$$

where $R_{d}$ is the rutting depth (mm), $\varepsilon_{p}$ is the permanent strain $(\mathrm{mm} / \mathrm{mm})$, and $h$ is the total thickness $(\mathrm{mm})$ of the asphalt concrete layer. $\varepsilon_{p}$ is evaluated based on the model developed in [17] as follows:

$$
\begin{aligned}
& L E_{P}=-34.463+0.983 \log N^{(0.00973 T 0.00284 S)}+ \\
& 1.961 \log T+1.812 \log S+0.656 \log D-37.277 \log B- \\
& 4.951 \log F-1.455 \log A-1.93 \log M
\end{aligned}
$$

where $L E_{P}$ is the $\log$ of accumulated permanent micro strain at the $N^{\text {th }}$ load repetition, $T$ is the test temperature $\left({ }^{\circ} \mathrm{C}\right), S$ is the stress level (psi), $D$ is the applied stress duration (s), $B$ is the percentage absorbed asphalt (by weight of aggregates), $A$ is the percentage of air voids, $M$ is the percentage of voids in mineral aggregates, and $F$ is the voids filled with asphalt. Similarly, using the trend of variation in RD with ESAL, as depicted in Figure 11, the values of RD for both the predicted and the measured data are closed. Therefore, the use of repeated load tests to predict $\mathrm{RD}$ is significantly accurate and reliable.

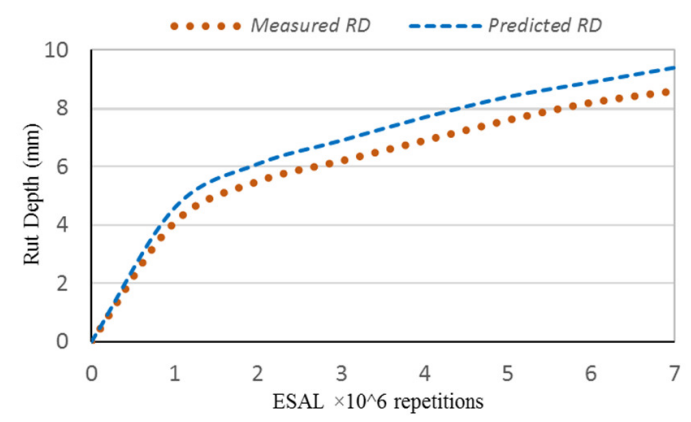

Fig. 11. Comparison between the predicted and the measured rut depths for various ESAL repetitions.
In general, to evaluate the rutting resistance properly the parameters from unconfined RLTs in $[9,14]$ can be used.

\section{CONCLUSION}

In this study, the power-law model was used to obtain parameters for simulating the permanent deformation of the asphalt layer under uniaxial repetitive and static compression loads. The results indicated that the accumulated plastic strain for the repeated load test was higher than that of the static load test for various mixture properties and climatic conditions (temperature). VESYS $5 \mathrm{~W}$ was used to predict the rut depth at the asphalt concrete layer subjected to equivalent single-axle loads. The $\alpha$ and $\mu$ parameters exhibited a considerable impact on the predicted rut depths. Finally, the results of this study indicated a high difference between the above two tests. The predicted rut depth based on repeated load tests was in reasonable agreement with the actual rut depth.

\section{REFERENCES}

[1] O. M. Kunene and D. Allopi, "Comparison Between Conditions of Major Roads Within and Outside the Port of Durban," Engineering, Technology \& Applied Science Research, vol. 3, no. 1, pp. 363-367, Feb. 2013, https://doi.org/10.48084/etasr.263.

[2] R. Garba, "Permanent deformation properties of asphalt concrete mixtures," Ph.D. dissertation, Norwegian University of Science and Technology, Trondheim, Norway, 2002.

[3] E. R. Brown and S. A. Cross, "A national study of rutting in hot mix asphalt (HMA) pavements," NCAT, Auburn, AL, USA, NCAT Report 92-05, Feb. 1992.

[4] J. Morris, "The prediction of permanent deformation in asphalt concrete pavements," 1973.

[5] AASHTO Guide for Design of Pavement Structures, 4th ed. Washington DC, USA: AASHTO, 2002.

[6] R. B. Leahy, "Permanent deformation characteristics of asphalt concrete," Ph.D. dissertation, University of Maryland, College Park, MD, USA, 1989.

[7] K. E. Kaloush, "Simple performance test for permanent deformation of asphalt mixtures," Ph.D. dissertation, Arizona State University, Tempe, AZ, USA, 2001.

[8] K. Jadidi, M. Khalili, M. Karakouzian, and S. Amirkhanian, "Toughness, Tenacity and Maximum Initial Strength of Rubber Modified Asphalt Binders," Engineering, Technology \& Applied Science Research, vol. 9, no. 1, pp. 3765-3769, Feb. 2019, https://doi.org/10.48084/etasr.2526.

[9] "Simple Performance Tests: Summary of Recommended Methods and Database," Transportation Research Board, NCHRP Report 547, Jun. 2006. https://doi.org/10.17226/13949.

[10] Standard Specifications for Highway Bridges: 2002, 17th ed. Washington DC, USA: AASHTO, 2003.

[11] M. W. Witczak, "Development of the 2002 guide for the design of new and rehabilitated pavements-flexible pavements overview," Hot topics, 2001.

[12] C. L. Monismith and A. A. Tayebali, "Permanent deformation (rutting) considerations in asphalt concrete pavement sections (with discussion and closure)," in Association of Asphalt Paving Technologists, 1988, vol. 57, pp. 414-463.

[13] C. L. Monismith et al., Permanent Deformation Response of Asphalt Aggregate Mixes. Strategic Highway Research Program, 1994.

[14] M. W. Witczak, K. Kaloush, T. Pellinen, M. El-Basyouny, and H. Von Quintus, "Simple Performance Test for Superpave Mix Design," Transportation Research Board, NCHRP Report 465, 2002.

[15] A. R. Archilla, L. G. Diaz, and S. H. Carpenter, "Proposed Method to Determine the Flow Number in Bituminous Mixtures from Repeated Axial Load Tests," Journal of Transportation Engineering, vol. 133, no. 
11, pp. 610-617, Nov. 2007, https://doi.org/10.1061/(ASCE)0733-947X (2007) 133:11(610).

[16] M. Irfan, Y. Ali, S. Iqbal, S. Ahmed, and I. Hafeez, "Rutting Evaluation of Asphalt Mixtures Using Static, Dynamic, and Repeated Creep Load Tests," Arabian Journal for Science and Engineering, vol. 43, no. 10, pp. 5143-5155, Oct. 2018, https://doi.org/10.1007/s13369-017-2982-4.

[17] A. H. Albayati, Permanent Deformation Prediction of Asphalt Concrete Under Repeated Loading, vol. 129. Baghdad, Iraq: University of Baghdad, 2006.

[18] T. L. J. Wasage, G. Ong, T. F. Fwa, and S. A. Tan, "Laboratory evaluation of rutting resistance of geosynthetics reinforced asphalt pavement," Journal of the Institution of Engineers, vol. 44, no. 2, pp. 29-44, 2004.

[19] C. L. Monismith, N. Ogawa, and C. R. Freeme, "Permanent deformation characteristics of subgrade soils due to repeated loading," presented at the 54th Annual Meeting of the Transportation Research Board, Washington DC, USA, 1975.

[20] W. J. Kenis, Predictive design procedures, VESYS users manual: An interim design method for flexible pavements using the VESYS structural subsystem. National Technical Information Service, 1978.

[21] X. Qi and M. W. Witczak, "Time-Dependent Permanent Deformation Models for Asphaltic Mixtures," Transportation Research Record, vol. 1639, no. 1, pp. 83-93, Jan. 1998, https://doi.org/10.3141/1639-09. 